\section{THE GENESIS OF LIMBS 1}

II.

In those huge marine reptiles of the secondary period, the Ichthyosaurus and the Plesiosaurus, we neet with the most complete serial symmetry between the fore and the hind limbs. In the Plesiosaurus, not only are the bones of the hand and foot completely alike, but the same is the case with those of the upper arm and thigh and those of the fore-arm and leg.

In the Ichthyosaurus there is a similar resemblance between the fore and hind limbs, with the further curious similarity that in both hand and foot the very numerous digital bones are so disposed as to indicate that the number of the digits exceeded five.

When we descend from reptiles to batrachians we again find in the tailed forms a remarkable and exceptional serial homology in the bones and cartilages of the limbs. Thus, through the great descending series of forms from man down to reptiles and efts, we find that there is one fundamental type of limb. In all such creatures the limbs are never more than four, they are divisible into two pairs, which always possess complete bilateral and more or less clearly marked serial symmetry. This serial symmetry is generally more or less disguised owing to the different uses to which the two pairs of limbs are respectively put. Yet whatever such uses and needs may be, whether the limbs be formed simply for locomotion, as in the horse; for grasping, as in the ape ; for flying, as in the bat and bird; or for swimming, as in the seal and the large extinct reptiles before referred to, we find the same limb segmentation running through all in both limbs.

1. An upper limb segment (upper arm and thigh).

2. A lower limb segment (fore-arm and leg).

3. A root part of the extremity (wrist and ankle).

4. A middle part of the extremity (mid-hand and midfoot).

5. A terminal part of the extremity (the fingers and toes, i.e., the digits).

In the great class of fishes an altogether different set of conditions obtains. The parts in fishes which answer to the fore limbs of the creatures hitherto considered, are the pectoral and the ventral fins. In them we find a number of delicate structures, "fin-rays," supported by bones or cartilages which have no obvious, even remote resemblance to the bones or cartilages of the limbs of batrachians, reptiles, birds, or beasts. The pectoral limbs are indeed attached to a shoulder girdle, but the ventral fins are appended only to bones or cartilages which lie amongst the muscles of the ventral surface of

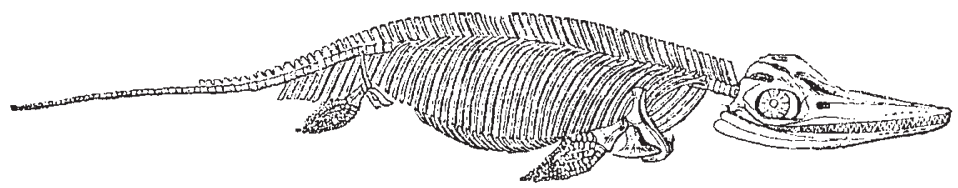

FIG. 12,-Skeleton of an Ichthyosaurus.

the body and hardly ever even approach the superincumbent vertebral column. In Lophizus, indeed, amongst bony fishes, these supporting structures do ascend somewhat, and the same is the case in Callorhynchus and Chincera amongst the cartilaginous fishes. Yet even here these pelvic structures are far from reaching the vertebral column.

In the fishes, which are in many respects most like the

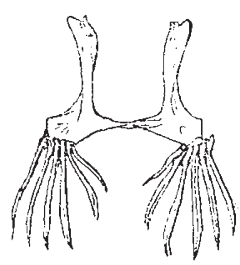

Fic. 14 .



FIG. 15.
Fig. 14. - The two ossa innominata of the Angler-fish (Lophizu), showing the ascending processes which simulate ila. The fin-rays are attached to the outer-ventral margin of each os innominatum.

Fig. 15.-Cartilaginous skeleton of a limb of Ceratudics.

higher animals, i.e., in the sharks and rays, the pectoral and ventral fins are not both formed in the same manner, but their structure differs considerably in different species.

The pectoral fin is supported by a number of carti-

$$
\text { Continued from p. } 284 \text {. }
$$

laginous rays which rest upon three basal cartilages lying nearest to the slender girdle and called respectively the Propterygizm, the Mesopterygium, and the Metapterygizm (see Fig. I7). The ventral fin is smaller, and consists of cartilaginous rays appended to a basal cartilacre which is suspended from the pelvic cartilage, to which latter some rays may also be directly attached.

In one very exceptional form, the ancient triassic fish still surviving in Queensland, Ceratodus, the limb-skeleton is sui generis. It consists of a median longitudinal series of cartilages, whence other smaller cartilages diverge on each side, the whole structure tapering to its distal end.

We see then, now, the answer to one of our initial questions, "What do our limbs stand for as compared with the bodies of other animals," and may proceed to another of those questions, namely, "Why are our limbs so much alike and yet so different?" We form one of a series of creatures with digit-bearing limbs (all vertebrates above fishes), all presenting similar resemblances and differences in varying degrees. The differences between our limbs are manifestly due to difference of function, but the resemblance may be due to one of two causes:-(x) The conservation of a complete serial symmetry present in the earliest vertebrate types, or (2) The action of internal polar force, tending to educe serial symmetry when such symmetry does not interfere with function. In other words, it may be due either ( $\mathrm{I}$ ) to genetic homogeny, or (2) to intra-organic homoplasy.

It appears to me impossible that it can be clue to tho former cause, for even if the first pairs of limbs ever formed were completely similar, which I by no means regard as certain, still the detailed resemblances found in animals high up in the scale cannot have continued uninterruptedly from such primitive forms. Even if we consider that the complete serial homology in the limbs of the tortoise, Chelydra, might be primitive, the limb of Hyrax, Perodicticus, and Nycticebus cannot owe their peculiar serial resemblances ${ }^{1}$ to the survival of primeval conditions.

I See "Genesis of Species," sec ond edtion, p. zor. 
But the action of an internal polar force is evidenced by other phenomena of pathology and teratology, which come to the aid of comparative anatomy in demonstrating its existence, Thus we very often see that parts which are serially or bilaterally symmetrical, are abnormally affected in a similar manner, ${ }^{1}$ as recorded by Sir James Paget, Dr. William Budd, Prof. Burt Wilder, and others, and the same is the case with congenital deformities. ${ }^{2}$

Perhaps, however, the most curious and instructive are those presented by some of our domestic birds. In birds we have found the serial symmetry of the limbs reduced almost to its minimum - the leg and foot being so widely different from the wing. In trumpeter pigeons and some bantams, however, the feet, which usually are naked, become abnormally furnished with feathers (technically called "boots"), which may be even longer than the wing feathers, and are developed from that side of the foot which corresponds with the feather-bearing side of the hand. Moreover, in ordinary pigeons, though the digits of the hand are completely united together, while the toes of the foot are free, but in "booted" pigeons the outer toes become more or less united together by skin like the fingers.

With facts such as these it seems to me unreasonable to deny the existence in each animal (which as a whole is a visible unity) of an innate polar force tending to carry out development in definite directions, but liable to have its action and effects modified by the environment.

We may now turn to those other initial questions, Whence have limbs such as ours arisen? What is a limb?

As to the first question: The digit-bearing limbs of man, beasts, birds, reptiles, and batrachians are usually supposed to have been derived from structures having more or less resemblance to the paired fins of fishes, but the path which the genetic process has followed is differently represented by different evolutionists.

As to the second question, i.e., as to the essential nature of vertebrates' limbs, of whatsoever kind, different vievs have also been maintained. By some anatomists they have been regarded as parts which have in one way or another been derived from the axial skeleton, by others they have been represented as skeletal structures appended to, but not derived from the axial skeleton.

In I 843 Oken taught the extremely fanciful doctrine that arms and legs are so many liberated ribs, and Carus followed him to a certain extent, teaching that they are essentially elements radiating from the exterior of a riblike arch.

In 1848 Owen propounded the view that they are diverging appendages attached to ribs like the uncinate processes of birds, and he compared them to the branchiostegal rays of fishes, He also taught that the shoulder and pelvic girdles are modified rib arches.

In I 852 Maclise represented the limbs as modified ribs, the parts beyond the elbow and the knee, however, corresponding with the interspinus bones and fin rays of fishes' azygos fins.

In 1857 Goodsir described them as radiating actinopophyses. ${ }^{3}$

In 187 I Humphrey represented the limbs as modified portions of a primitively continuous inferior azygos fins.

In 1872 Gegenbaur threw out the suggestions which he has since (1874 and 1876) more definitely adopted, that the shoulder girdle is a modified arch of similar nature to the branchial arches, the limbs having been formed from rays diverging outwards from such an arch. He also considers the skeleton of the azygos fins as the separated ends of the neural and hoemal spines of the vertebral column."

Owen and Gegenbaur consider the paired and azygos

"See "Genesis of Species," second edition, p. 205

L Loc. cit., p. 202.

3 Fidinburgh New Pkil. Foumal, vol. v. (new series), I857, p. 178 .

4 "Grundriss d. Vergl. Anat.," I874, p. 488. limbs to be two fundamentally different structures, and Huxley ${ }^{1}$ calls their sustaining bones or cartilages "elements of the exoskeleton."

The fundamental distinctness between the paired limbs and the axial system appears to have been held by Cuvier and by Huxley. I advocated the same view in I $870, "$ and I have since expressed ${ }^{3}$ my conviction "that the appendicular skeleton is no mere portion of the axial skeleton, but a distinct system of parts appended to, and more or less closely and variously connected with, the axial system." To this conviction I now adhere more firmly than ever. I have also been long convinced that the shouldergirdle could not be (as Gegenbaur thinks) a branchial arch, or be formed of coalesced branchial arches, as also that the branchial arches could not be (as some have supposed) serially homologous with rib-arches. For the branchial arches are within the aortic vessels, which vessels I took ${ }^{4}$ to

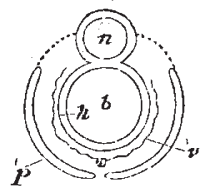

F.rg. 16.-Diagram of the condition of the skeleton in the branchial region of some sharks (transverse vertical section), $-n$, neural canal; $b$, alimentary canal, surrounded by $h$, the branchial arches (splanchnapphyses); $"$ s the aortic vessels, extending up outside the branchial arches and inside the paraxial system $(\not)$, here represented by certain external branchial cartilages.

"indicate the line of the pleuro-peritoneal division of the ventral laminæ" of the embryo. This conviction has been remarkably justified by Mr. Balfour's recent discovery of the continuation (in embryo elasmobranchs) of the pleuro-peritoneal cavity into the head, and externally to their aortic vessels. ${ }^{6}$

Prof. Parker has recently suggested" that the "extrabranchials" of the dogfish may be homologous with the scapulo-coracoid, but I am persuaded this is not the case.

In $1876 \mathrm{Mr}$. Balfour described ${ }^{7}$ the development of the limbs of elasmobranchs as "special developments of a continuous ridge on each side, precisely like the ridges of epiblast which form the rudiments of the unpaired fins." Since then the paired fins arise in the same way as the azygos fins; they all probably belong to the same category of peripheral, non-axial structures. Moreover, since this is the mode of origin in the individual, there of course arises an $d$ priori probability that it was the mode of origin in the race, and that the primeval vertebrate limbs were a pair of continuous lateral folds, serving to balance the body in swimming.

Now I conceive it will hardly be disputed that when supporting hard structures were first developed in the azygos fins they had the form they so generally still present, of a longitudinal series of numerous similar, separate, rod-like structures. But the skeleton of the paired, especially of the pectoral fins, is very different from this. The interesting questions, therefore, arise : (I) Whether any azygos fins present characters approximating them to the normally developed paired fins? and (2) Whether any paired fins present characters approximating them to the normally developed azygos fins?

A detailed account of some recent dissections of fish-fins made with a view to answer these questions-dissections effected through the kindness and liberality of Dr. Giunther, at the British Museum-have been lately ${ }^{8}$ communicated to the Zoological Society. The result of those dissections

I "Anat. of Vertebrates," p. 43.
2 Linn. Trans., vol. xxvii. p. 388.

3 "Lessons in Elementary Anatomy," 1873, p. 230

4 Lirn. Trans., l.c.

5 Cambridge Fournal, vol. xi. part 3, April, 8777, p. 474. The author's words are :- "It occupies a position on the outer side of the aortic trunk of its arch."

6 "Morphology of the Skull," p. 343.

7 Cambridge fournal, vol, xl. part r, p. $132 . \quad 8$ Vol. v., 1878 
is that I have found such varying degrees of coalescence between the cartilaginous rays of the dorsal fins as may go far to bridge over the differences between the two orders of fins, while the close resemblance sometimes presented by paired fins to azygos fins (some of the ventrals being so nearly like certain dorsal and anal fins), is such that I think a conclusion in favour of their essential similarity of nature cannot be successfully contested.

As to the dorsal fin, I have found incipient coalescence between the rays, in Scyllian canicula, Ginglymostoma cirratum, and others, but in Notidanus cinereus I have found this process carried to such a degree, that there comes to be one continuous basal cartilage to the dorsal margin of which the cartilaginous rays are appended.

In Pristis and Pristiophorus I found a very interesting condition which I am not aware has been described. The rays in these genera repose upon solid cartilages which are absolutely continuous with the subjacent axial skeleton. I would suggest that the lateral pressure of the saw-like rostrum must be aided in these fishes by such a firm attachment of the dorsal fin cartilages to the vertebral column.

ST. GEORGE MIVART

(To be continued)

\section{A HUNTING WASP}

THE following interesting account of a chase between a wasp and a spider has been forwarded to us by Mr. Henry Cecil, who, it may be remembered, wrote to NATURE on the subject (vol. xvii. p. 38r) :-

The Piræus, Athens, June 19

DEAR SIR,-Your letter of April 5, and the two numbers of NATURE, reached this during my absence in Thessaly, which must be my apology for not having sooner replied to your letter.

Though more than thirty years have elapsed since the circumstance alluded to, I perfectly remember the curious chase I witnessed of a very large and powerful huntingspider by a species of wasp.

I was sitting one summer's afternoon at an open window (my bed-room) looking into a garden, when I was surprised to observe a large and rare species of spider run across the window-sill in a crouching attitude. It struck me the spider was evidently alarmed or it would not have so fearlessly approached me. It hastened to conceal itself under the projecting edge of the windowsill inside the room, and had hardly done so when a very fine large hunting-wasp buzzed in at the open window and flew about the room evidently in search of something. Finding notbing the wasp returned to the open window and settled on the window-sill, running backwards and forwards as a dog does when looking or searching for a lost scent. It soon alighted on the track of the poor spider, and in a moment it discovered its hiding-place, darted down on it, and no doubt inflicted a wound with its sting. The spider rushed off again and this time took refuge under the bed, trying to conceal itself under the framework or planks which supported the mattress. The same scene occurred here, the wasp never appeared to follow the spider by sight, but ran backwards and forward in large circles like a hound. The moment the trail of the spider was found the wasp followed all the turns it had made till it came on it again. The poor spider was chased from hiding-place to hiding-placeout of the bedroom across a passage and into the middle of another large room, where it finally succumbed to the repeated stings inflicted by the wasp. Rolling itself up into a ball the wasp then took possession of its prey, and after ascertaining it could make no resistance, tucked it up under its very long hind legs just as a hawk or eagle carry off their quarry, and was flying off to its nest, when $I$ interposed and secured both for my collection.

Both insects were rare ones, and during the ten years I collected as a field naturalist in Greece, I don't remem- ber ever seeing more than three or four specimens of either that species of wasp or spider.

The wasp was a hunting one (a female) about an inch and-a-half long, a very finely formed insect, which for gracefulness of form and beauty of colouring is entitled to be placed at the head of its species. The legs of this kind of wasp are very long and of a dark chocolate brown. It runs very quickly. The wings are a lightbrown with dark-brown tips and long and powerful, and the body beautifully mottled with pale yellow and brown. It has very long fine antennæ. It is not an English species, but probably exists in Spain, the south of France, and Italy.

The spider, too, was a rare one. One of the largest Greek hunting-spiders, nearly as large in the spread of its legs as the flesh-coloured tarantula though without his powerful crab-like pincers. The one I allude to must have covered at least three inches in circumference when its legs were fully extended. It was of a dull mottled brown colour on the upper surface of the body. Very difficult to distinguish from the ground. The lower part of its body was, however, brilliantly coloured, the long legs, or arms, being marked underneath with velvet-like looking black and white rings. The head, thorax, and abdomen were of a velvety black, the lower portion of the latter surrounded with a bright orange ring.

There is only one error in the account given by you in NATURE, that is, that you were under the impression I told you, that kind of spider was the common prey of that species of wasp. You must have misunderstood me.

I. I do not think that particular kind of spider is sufficiently common for this to be the case.

2. I never saw a similar conflict of the kind before or after, which as it was in a room, and not in the grass, where I presume such encounters usually take place, I observed under exceptionally favourable circumstances.

I am certain the spider left no web or thread behind it. I cannot be sure, however, that, as it had evidently been attacked by the wasp before entering my room, a small quantity of liquid may not have exuded from its wounds, which may have helped the wasp in tracking it. I have no doubt myself that insects have the sense of smell, and probably much more developed than our own. No one, as you remark, who has sugared for moths, or seen the large sphingidæ hovering over the strongest scented flower at night, or employed a caged female moth as a lure to her male admirers, can, I think, doubt this. If so, let them put a saucerful of honey in a corner of a room opening into a garden, throw open the window, and see how soon the bees, wasps, \&c., will be attracted to the honey.

There is a tradition in the east that one of the tests by which the Queen of Sheba tried to prove the wistom of Solomon, was placing on a table before him two bouquets, one of artificial, and the other of natural flowers, and requiring that he should say which were the real and which the artificial, without moving from his throne. Solomon ordered the windows to be thrown open, and in flew the bees, \&c., which went at once to the real flowers.

Whether the senses of insects, birds, and what we call the lower creation, are similar to ours in every respect, it is very difficult to say. No doubt a dog, if he could speak, would say a man had not the sense of smell, and would prove that his nose was worse than useless to him. An eagle or hawk would say that men and moles, \&cc., have only the rudiments of eyes, and so on.

Man, with five very imperfectly developed senses (who can say that there are not twenty senses), is the only animal that is dogmatical, and denies all he cannot understand. The oracle of Delphi said "Socrates was the wisest man in Greece, because he was the only man who knew he knew nothing." Yours faithfully,

To Henry Cecil, Esq., Bournemouth. 